\title{
Editorial
}

\section{Acta Pharmacologica Sinica: Celebrating 30 years of publishing}

Jian DING

Editor-in-chief, Acta Pharmacologica Sinica

Acta Pharmacologica Sinica (2010) 31: 1013-1014; doi: 10.1038/aps.2010.160

Acta Pharmacologica Sinica (APS) is now celebrating 30 years of publication. I am happy to summarize what has been accomplished over the past three decades. First I would like to sincerely thank the founding editor-in-chief (1980-2003), Professor Guang-sheng DING. He is well known for his strictness, tireless work ethic, and remarkable editing skills. He helped hundreds of pharmacologists bring their contributions to publication. Second I would like to thank the former editor-in-chief (2003-2007), Professor Kai-xian CHEN. Under his leadership, the impact factor of APS increased from 0.884 to 1.677. Third I want to thank each of the editorial directors, Shu-gai ZHANG, Wei-cheng WANG, Hong XIAO, and Minshu WU, as well as their editorial teams. Their great efforts have helped APS manage the editorial work efficiently and successfully and win several National Awards. Last but not least I owe a great deal of gratitude to our authors and reviewers for their strong support. Their substantial contribution to the progress of the journal cannot be overstated.

The first issue of APS was published in the autumn of 1980 in Chinese and changed into English in 1999. As time goes on, the number of outstanding manuscripts being submitted to APS continues to rise and the page number of APS has steadily increased from 256 pages in 1981 to 1716 pages in 2009. It presents quite a contrast to compare the content of some of our early issues to the papers that we are currently publishing. At the beginning, most of the research papers of APS were in the fields of traditional neuropharmacology and cardiovascular pharmacology. The subjects covered have gradually expanded over the 30 years, and now we are happy to see that the papers we publish cover diverse topics ranging from theoretical pharmacology to pharmacogenetics, pharmacoepidemiology, and bioinformatics. Our authorship is not only from mainland China but also from all over the world. Together we strive to provide a common vehicle for bringing together new concepts such as network pharmacology, translational medicine, and biomarkers that have launched a new era in pharmacology research.
Impact factor is one way to measure the quality of papers in a journal. It helps us evaluate a journal's relative importance, especially in the same field. APS was selected into the Science Citation Index in 1985. Since this time, although the impact factors of many journals in the pharmacology and pharmacy subject grouping have fluctuated, the impact factor for APS has increased substantially (Figure 1), with a 9-fold increase over the past 10 years.

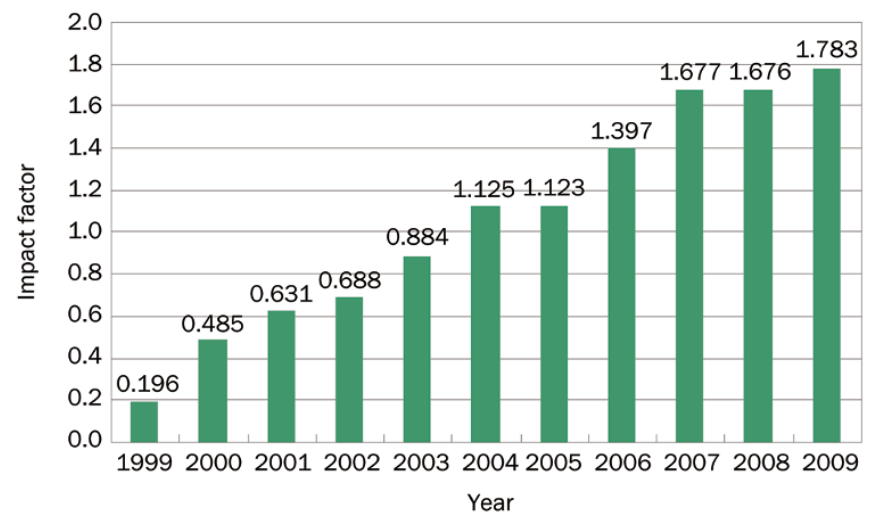

Figure 1. Impact factor of Acta Pharmacologica Sinica in recent years.

The most important mission of APS is to provide authors with timely and professional peer review and rapid publication of their manuscripts. To remove any bias from the review process, all manuscripts are independently considered by two or three reviewers from different countries (Figure 2). The international referee guarantees reliable information for making the final decision. The average time from receipt of new submissions to publication in print has greatly shortened to 5 months over the past few years. Now the average time for the first decision has decreased to 26 days. Advance online publication allows rapid publication of high-quality, peer- 


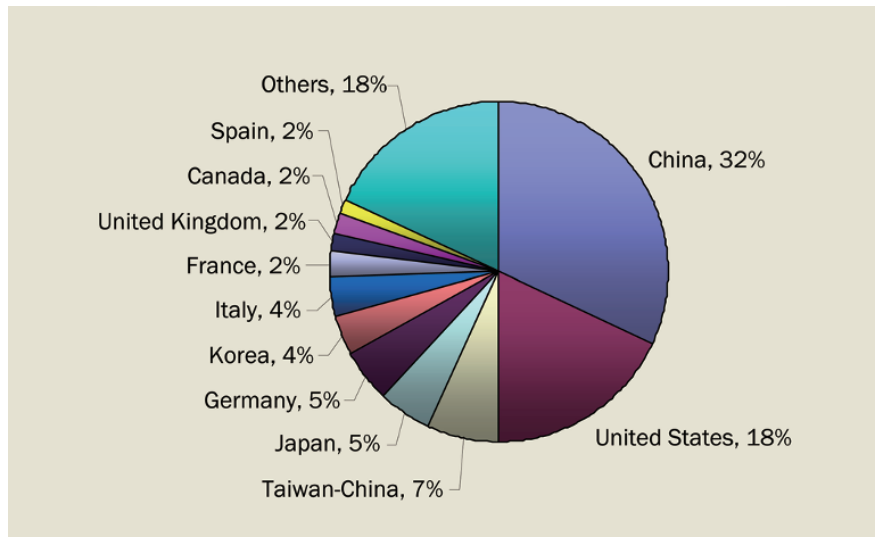

Figure 2. The international distribution of peer reviewers for APS.

reviewed research for the benefit of both readers and authors. All APS papers, including those published in advance online, are accessible and can be referenced formally by their digital object identifier (DOI) as soon as they appear on the website (http://www.nature.com/aps). We are delighted that NPG, which is renowned as one of the world's premier science publishers, has been co-publishing APS with us since 2009 .
We expect that the new partnership will help APS to go from strength-to-strength in the future.

As China's leading international journal in pharmacology and pharmacy, APS has contributed greatly not only to the development of the discipline as a whole but also to new drug $R \& D$ in China. However, we have to face the gap in the global academic impact compared with the top-tier international pharmacology journals. We have considerable challenges to meet, with a need for high-quality papers from all over the world to increase the appeal of the journal to a broad readership. With strong support from our international editorial board, we believe that APS will be the platform for publishing excellent papers that are of wide biological significance in the multidisciplinary field of pharmacology and related life sciences, from experimental to clinical. Please visit APS online: past, present, and future (http://www.chinaphar.com).

To commemorate this 30th anniversary of APS we have organized a special issue, which we hope you will enjoy. All articles have been contributed by our editorial board members, including 5 perspective articles, 23 review articles, and 1 original article. With their broad appeal and accessible style we hope that our readers will enjoy the articles this special issue brings together.

Let's share the celebration of our 30th anniversary! 